\title{
Misrepresentation in tsunami warning signage: iconic denial
}

\author{
Wendy S. Shaw $\cdot$ James Goff
}

Published online: 3 February 2015

(C) Springer Science+Business Media Dordrecht 2015

[B]lue and white signs depict ... a series of waves and a stick figure running uphill that alert residents and visitors to the fact that they are in a tsunami-vulnerable area. These tsunami warning signs, which were created as part of an Oregon Sea Grant effort, have spread not only to other U.S. states and territories, but also to other countries ... 'it's certainly gratifying [to see] how it's caught on' says emeritus Professor Jim Good. (Goss 2008, 7).

Hokusai's 'Great Wave off Kanagawa' is an iconic image (Fig. 1). Created in Japan during the Edo period (c. AD 1831) and celebrated through countless reproductions, particularly online (Google it in 'images'), this depiction of a large breaking, 'rogue' wave (Dudley et al. 2013) has been adopted as a symbol for tsunami warning signs globally, as described above. In this short commentary, we support the position that this uncritical acceptance of an incorrect image is highly problematic and potentially dangerous, and that the persistence of this misrepresentation is based, in part at least, on acceptance of the iconic image rather than science. This needs to be challenged.

W. S. Shaw $(\bowtie) \cdot$ J. Goff

University of New South Wales, Sydney, NSW, Australia

e-mail: w.shaw@unsw.edu.au
When catastrophic wave events occur, individuals are so fascinated by the sheer might of nature that they sometimes put themselves in harm's way. For example, during Hurricane Sandy on the eastern seaboard of the USA in October 2012, individuals ventured perilously close to large and powerful surf breakers to witness the spectacle (e.g. Taylor 2012, photo 8). The success of the film 'Deep Impact' also demonstrates the obsession with big waves. It is hard to forget the image of the final moments of the lives of Tea Leoni's character Julie, and her father, spent standing embraced on a beach as the huge, and impossible, Hokusai-like wave descends.

While the Hokusai image is indeed tantalising, Cartwright and Nakamura (2009) identified that the association between Hokusai's rendering and tsunamis is semantic, simplistic, and potentially dangerous. They argued that:

the word tsunami is Japanese, and Hokusai is also Japanese, ergo Hokusai's wave must be a tsunami ... this confusion [with a storm wave] may be detrimental to attempts to ... recognize ... [a] tsunami [by] identifying the withdrawal of the sea like an exceptionally low tide, in many instances the first hint of a tsunami (Cartwright and Nakamura 2009, 14; Fig. 2).

While it is not always a drawdown (withdrawal of the sea) that occurs first, the question remains as to why we persist with an image that is wrong in most cases. While it might be argued that the effectiveness of the signage rests not on literal interpretation, a preliminary study of 


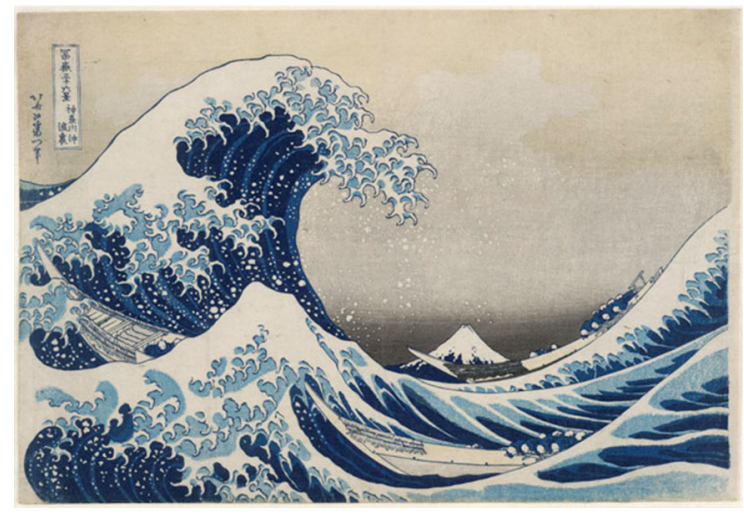

Fig. 1 Hokusai's Hokusai's 'Great Wave off Kanagawa' Japan, Edo period, c.AD1831 (Source: http://www.britishmu seum.org/explore/highlights/highlight_image.aspx?image=hoku sai.jpg)\&retpage=16638)

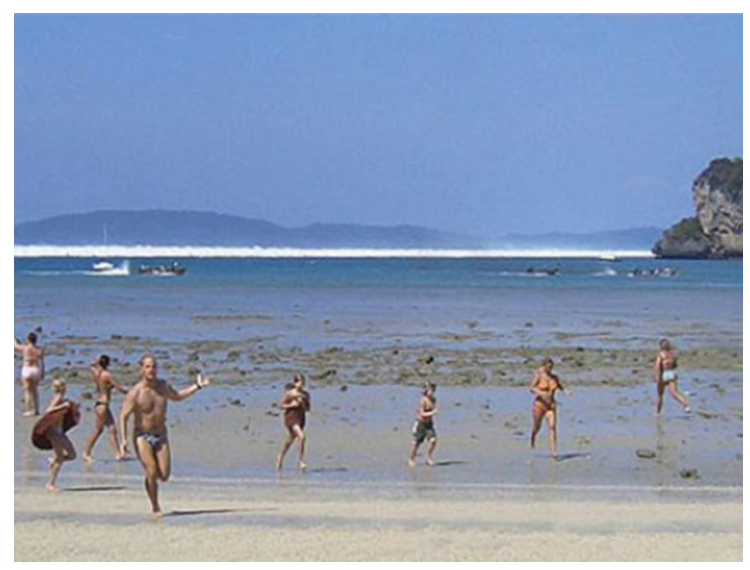

Fig. 2 'First hint': drawdown of a tsunami in Thailand, 2003 (Source: http://picturetsunami.blogspot.com.au/2012_04_01_ archive.html) the effectiveness of warning signs in Thailand found that "Most signs as symbols ... are adapted from international hazards symbols. Though, some of those signs and symbols can be underst[ood] ... a number of them are still not appropriate and adaptable by the local community" (Imsuwansakorn 2012, 43). More research is clearly needed on the efficacy of international hazard symbols, and in particular, the utility of incorrectly depicted tsunamis (for instance, Fig. 3a) that then need to be interpreted in situ.

We remain intrigued also by why tsunami science has succumbed to the seductive image of the Hokusaibased wave. Many authors unwittingly, or uncritically, include the incorrect wave images, represented in the ubiquitous tsunami warning signage, in publications (for example, but not limited to Bernard 2001; Clague and Munro 2003; Levy and Gopalakrishnan 2005; Dahdouh-Guebas et al. 2005; Kim et al. 2013). Of perhaps most concern is the International Tsunami Information Center's stylised use of the wave in its Tsunami Glossary which, while going to great length to explain the characteristics of a tsunami and the erroneous use of terms such as "tidal wave" to describe it, continues to subliminally propagate the Hokusai wave myth (IOC 2013).

The origin of this runaway train of misrepresentation is unclear, as is the precise moment of association between Hokusai's wave and tsunamis. According to Goss $(2008,7)$, we know the origin of the sign itself, and that it was "modeled after hurricane evacuation signs on the East [US] Coast .... [and designed by a] graphic design specialist with the university's College of Agricultural Sciences and Extension". However,
Fig. 3 a Classic tsunami warning signage. b The 'surfy furphy' sign (Source: http://indosurflife.com/ 2013/12/why-you-cantsurfa-tsunami/) (a)

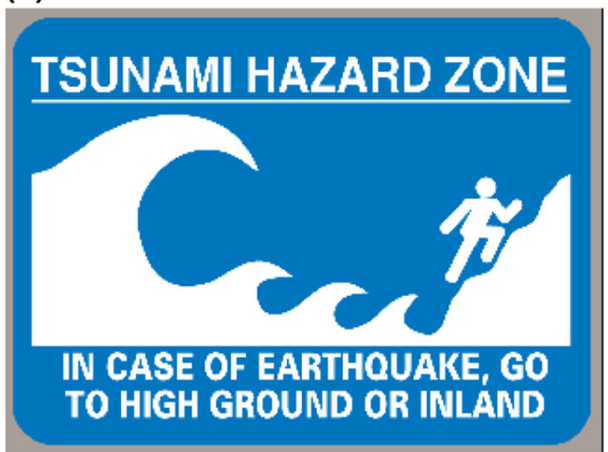

(b)

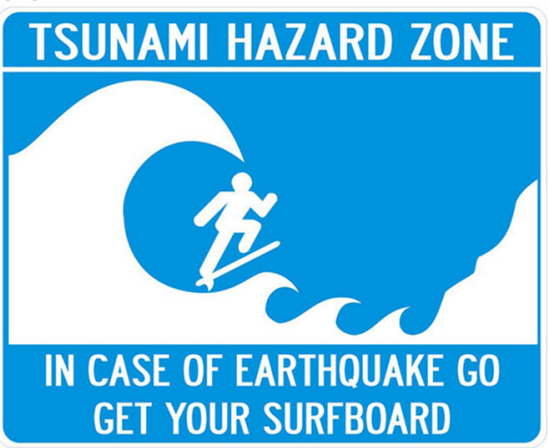




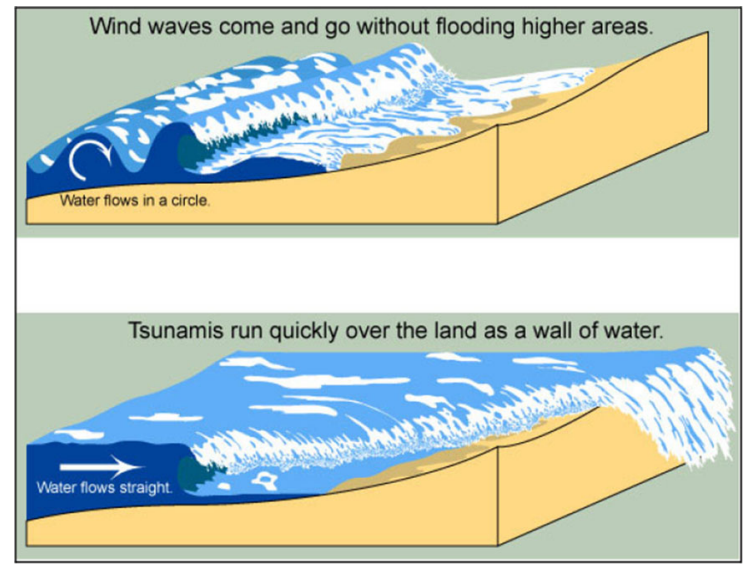

Fig. 4 Tsunamis versus "normal" waves (Source: http:// earthweb.ess.washington.edu/tsunami/images/tsulg.jpg); possible modification of existing sign

the association between tsunamis and Hokusai's wave probably occurred earlier, sometime between 1961 and 1964 (Cox 2001). Indeed, in a discussion of the characteristics of tsunamis, Wilson (1964) incorrectly described Hokusai's wave as portraying the crest of a great tsunami. In 2015, the image of tsunamis as breaking waves continues, and has inevitably led to public confusion. This was clearly demonstrated when surfers attempted to ride tsunamis as though they were surf-able waves (Fig. 3b). This 'surfy furfy' led to a blog that explains why this is near impossible.

According to University of Hawaii at Hilo.... You can't surf a tsunami because it doesn't have a face. Many people have the misconception that a tsunami wave will resemble the 25 -foot waves at [famous surfing beaches], but this is incorrect: those waves look nothing like a tsunami. On the contrary, a tsunami wave approaching land is more like a wall of whitewater. It doesn't stack up cleanly into a breaking wave; only a portion of the wave is able to stack up .... Since the wave [can be] ... 100 miles long and the tail end of the wave is still traveling at $500 \mathrm{mph}$ (about 800 $\mathrm{kph}$ ), the shore end of the wave becomes extremely thick, and is forced to run far inland, over streets and trees and houses. (http:// indosurflife.com/2013/12/why-you-cant-surf-atsunami/, last accessed 19.1.2015)

It appears that while surfers have used social media to broadcast the difference between tsunami and surf- able waves, safety science is unwilling to make the distinction preferring to stick with the Hokusai-based image. Professor Good (Goss 2008, 7) believes that the signs have been successful; that they have a "simple clear message ... [they are a] graphical depiction of the response a person should have in the event of a strong earthquake", which does not explain the use of the image of a big wave-tsunamis, not big waves, result from earthquakes. It is not clear if the striking simplicity of the Hokusai-based image is so mesmerising, and memorable, that it has become far too entrenched to change. The danger is that the error has been perpetuated to the point where it has become a false truth-tsunamis are surging bodies of water. They are definitely not (surf-able) waves. Yet, this error in signage propagates a misconception based on a simple failure to realise that tsunamis often have such a small steepness to them that they often cannot be recognised as the waves portrayed in the stylised Hokusai images. But, as Cox $(2001,92)$ points out:

I must admit ... that I can think of no substitute whose artistic attractiveness would approach that of representations of Hokusai's "Great Wave". Hence it seems unlikely that these representations will be replaced as tsunami icons.

The reality of death at the hands of nature ${ }^{1}$ (be it an earthquake, tsunami or other force), is therefore pitted against the difficulty of contemplation beyond the attractiveness of an image that may or may not work. The research is yet to be done, as the extent to which these signs save lives, and most importantly, if more would be saved if they were accurate, remains unknown. If replacing the powerful iconic image of Hokusai's "Great Wave" cannot be foreseen, or is highly unlikely for reasons beyond the control of safety science, it should be counterbalanced by stylised representations of the tsunami drawdown (for instance, modified using Fig. 4). Scientists might argue that this also misrepresents a tsunami's arrival at the coast since a drawdown (or the trough of the first wave) does not always arrive first. However, if it is used in conjunction with diagrams of the tsunami's arrival, as compared to that of 'ordinary' waves

\footnotetext{
${ }^{1}$ We use the term nature here in full acknowledgement that human-induced climate change impacts are not necessarily 'natural'.
} 
(Fig. 4), it may well be possible to develop better signage, and more informed science. We are not graphic artists who can design effective warning signs but we argue strenuously that even if the results are not as artistically attractive as the Hokusai-based image the point is (or should be) about saving lives, not signage/image attractiveness.

\section{References}

Bernard, E. N. (2001). Tsunami: Reduction of Impacts through three Key Actions (TROIKA). ITS Proceedings, 1, 1.

Cartwright, J. H. E., \& Nakamura, H. (2009). What kind of a wave is Hokusai's Great wave off Kanagawa? Notes and Records of the Royal Society Journal of the History of Science, 63(2), 119-135.

Clague, J. J., \& Munro, A. (2003). Tsunami hazard and risk in Canada. Natural Hazards, 28, 433-461.

Cox, D. C. (2001). The inappropriate tsunami icon. Science of Tsunami Hazards, 19, 87-92.

Dahdouh-Guebas, F., Jayatissa, L. P., Di Nitto, D., Bosire, J. O., Lo Seen, D., \& Koedam, N. (2005). How effective were mangroves as a defence against the recent tsunami? Current Biology, 15(14), 1337-1338.

Dudley, J. M., Sarano, V., \& Dias, F. (2013). On Hokusai's great wave off Kanagawa: localization, linearity and a rogue wave in sub-Antarctic waters. Notes and Records of The Royal Society, 67(2), 159-164.

Goss, H. (2008). Oregon tsunami signs go international. Coastal Services July/August 2008. http://coast.noaa.gov/ magazine/2008/04/article3.html. Accessed 19.1.2015.

Imsuwansakorn, P. (2012). The symbology development for hazard communication in Thailand. International Proceedings of Development and International Research, 57(8), 42-48. doi:10.7763/IPEDR.2012.V57.8.

IOC (Intergovernmental Oceanographic Commission). (2013). Tsunami Glossary 2013. UNESCO-IOC, Paris Technical series 85, p. 48.

Kim, D.S., Hong, S.J., Park, H.S. (2013). Analysis of evacuation system on tsunami disaster prevention in Korea. In Conley, D.C., Masselink, G., Russell, P.E., and O'Hare, T.J. (eds.), Proceedings 12th international coastal symposium (Plymouth, England), Journal of Coastal Research, Special Issue 65, 974-979, ISSN 0749-0208.

Levy, J. K., \& Gopalakrishnan, C. (2005). Promoting disasterresilient communities: The Great Sumatra-Andaman earthquake of 26 December 2004 and the resulting Indian Ocean tsunami. Water Resources Development, 21(4), $543-559$.

Taylor, A. (2012). Hurricane sandy in photos. The Atlantic. http://www.theatlantic.com/infocus/2012/10/hurricane-sandyafter-landfall/100396/. Accessed 14.10.2014.

Wilson, B. W. (1964). Generation and dispersion characteristics of tsunamis (pp. 413-444). Japan: Studies on Oceanography. Ocean Research Institute, University of Tokyo Press. 